\title{
Umbilical Cord Blood Tsh Level in Neonates: A Screening Tool For Congenital Hypothyroidism
}

\author{
Dr. Mani Shankar ${ }^{1}$,Dr. Raghunandanchoudhary ${ }^{2}$,Dr. Anil Kumarchaudhary ${ }^{3}$ \\ Department Of Pediatrics, Rajendra Institute Of Medical Sciences, Ranchi,India
}

\section{Introduction}

Congenital hypothyroidism is the most common preventable cause of mental retardation. Features of congenital hypothyroidism are non specific and difficult to identify in the neonatal period. They become prominent with increasing age. However the window period for neurological intervention has elapsed in most patients by this time.

\section{The female to male ratio is $2: 1$.}

If congenital hypothyroidism is diagnosed promptly and treated early irreversible mental retardation can be prevented. Neonatal screening programs for congenital hypothyroidism screening are widespread in developed countries for the last three decades and are fast gaining momentum in developing countries as well.

\section{Aims and objectives:}

The aim of neonatal screening program is to detect affected neonates and provide replacement to them as early as possible so that severe physical and mental handicap can be prevented by early treatment.To evaluate the effectiveness of cord blood TSH screening to detect cases with hypothyroidism.

\section{Methods}

A cross sectional study conducted on babies born in department of obstetrics and gynaecology,RIMS Ranchi. Umbilical cord blood sample was collected in a sterile container drawn from the umbilical cord incised at the time of birth. TSH level was estimated within 24 hours by chemiluminescent microparticle immunoassay (CMIA) method in department of laboratory medicine/biochemistry RIMS, Ranchi. All babies having the cord blood TSH values $\geq 20 \mathrm{mU} / \mathrm{L}$ were intimated and were advised to give fresh samples for T4 and TSH between 2-4 days of life.

sample size :200

inclusion criteria :1) babies born at rims,ranchi 2) babies born to mother with no history of thyroid disease exclusion criteria : mother on any thyroid medications.

\section{Result}

Number of confirmed case of congenital hypothyroidism was $1 / 200$. There were total 7 cord blood samples whose TSH values $\geq 20 \mathrm{mIU} / \mathrm{L}$ but a repeat test on 2-4 days of life confirmed $\mathrm{CH}$ in one of these samples. Mean TSH value female was $7.27 \pm 0.89 \mathrm{mIU} / \mathrm{L}$ while mean TSH value for male was $6.89 \pm 0.38 \mathrm{mIU} / \mathrm{L}$. Mean TSH value for preterm was $10.99 \pm 0.62 \mathrm{mIU} / \mathrm{L}$. Mean TSH value for term was $6.81 \pm 0.60 \mathrm{mIU} / \mathrm{L}$. Mean TSH value for post term was $4.38 \pm 0.75 \mathrm{mIU} / \mathrm{L}$.

\section{Discussion}

Present study was carried out in the department of Peadiatrics and neonatology,RIMS,Ranchi. TSH cut off Jvalues for screening of neonates: Initial TSH value $\leq 10 \mathrm{mIU} / \mathrm{L}-\mathrm{Normal}$ Initial TSH value 10.1-19.9mIU/L- Borderline Initial TSH value $\geq 20 \mathrm{mIU} / \mathrm{L}$ - Abnormal

These studies need larger sample size and stronger logistic effort with team approach.7.5\% of newborns in our series had values between 10.1-19.9mIU/L.This is the group which needs further evaluation to confirm thyroxine deficiency either acquired or congenital. 


\section{Conclusion}

Due to the practice of early discharge in our country cord blood estimation remains a very practical method for screening purpose. Use of cord blood TSH as a screening tool is an attractive method because of its simplicity and accessibility.The Indian Academy of Pediatrics recommends the use of cord blood samples for screening for congenital hypothyroidism. 